\title{
Qualidade do Cuidado: Estratégias Construídas com Trabalhadores da Enfermagem
}

\author{
Gonçalves, Naiane Glaciele da C.; Duarte, Cibeli da Rosa; Silveira, Rosemary Silva da; \\ Lunardi, Valéria Lerch; Saioron, Isabela; Fernandes, Geani Farias Machado \\ Universidade Federal do Rio Grande — naianeglaciele@gmail.com
}

Introdução: no compromisso com o cuidado do usuário é imprescindível o diálogo e a existência de espaços para que cada trabalhador possa envolver-se, sensibilizar-se, participar das decisões, o que requer respeito e estímulo à criticidade, à problematização e ao exercício de sua autonomia no ambiente de trabalho. Objetivo: Construir estratégias coletivas que contribuam para o fortalecimento do compromisso dos trabalhadores da enfermagem com o cuidado ao usuário. Metodologia: Pesquisa qualitativa, fundamentada em Freire. Participaram 24 trabalhadores de enfermagem de uma Unidade de Clínica Médica (UCM) de um Hospital Universitário (HU) do extremo sul do país. a coleta de dados foi desenvolvida em 11 encontros, buscando articular o diálogo e a problematização para que os trabalhadores direcionassem um olhar para si e para a realidade, compartilhando experiências com vista a sua transformação. Obteve-se a aprovação do Comitê de Ética. Utilizou-se a análise textual discursiva, a qual foi desenvolvida em quatro focos: "Desmontagem dos textos", "Estabelecimento de relações", "Captando o novo emergente", "Um processo auto organizado". Emergiram duas categorias: Promovendo o fortalecimento das relações interpessoais dos trabalhadores para o compromisso com o cuidado e a organização do trabalho como expressão do compromisso com o cuidado. Resultados: para a problematização dos trabalhadores de enfermagem, utilizaram-se algumas dinâmicas visando sensibilizá-los por meio da aproximação entre si, da valorização, do respeito, da necessidade de compreensão do outro para que cada um como parte do coletivo pudesse refletir acerca de sua importância e construir estratégias a fim de organizar e planejar o trabalho. Evidenciaram que é importante realizar críticas construtivas, elogiar, motivar a equipe a comprometer-se com a qualidade do cuidado ao usuário. Enfatizaram a importância de o enfermeiro exercer a supervisão e controle sobre as atividades da equipe, como uma ação necessária para assegurar a realização do cuidado. uma das estratégias para organizar o fazer dos trabalhadores consistiu da elaboração de um folder educativo para os usuários e da possibilidade de utilizar-se do diálogo como uma dimensão ética do fazer. Conclusão: Foi possível intensificar e valorizar o trabalho em equipe, fortalecendo as relações interpessoais e a abertura de espaços para o diálogo e a reflexão, possibilitando a tomada de consciência dos trabalhadores frente à necessidade de propor estratégias para modificar o contexto de trabalho. 0 respeito pelo fazer do outro, o fortalecimento dos laços de confiança e de amizade resgatados durante os momentos de sensibilização possibilitou amenizar os conflitos existentes e 0 estabelecimento de relações interpessoais mais favoráveis, os quais são fundamentais para fortalecer o compromisso com a qualidade do cuidado ao usuário.

Gonçalves, Naiane Glaciele da C.; Duarte, Cibeli da Rosa; Silveira, Rosemary Silva da; Lunardi, Valéria Lerch; Saioron, Isabela; Fernandes, Geani Farias Machado. Qualidade do Cuidado: Estratégias Construídas com Trabalhadores da Enfermagem. In: Anais do Congresso Internacional de Humanidades \& Humanização em Saúde [= Blucher Medical Proceedings, num.2, vol.1]. São Paulo: Editora Blucher, 2014. ISSN 2357-7282

DOI 10.5151/medpro-cihhs-10667 